\title{
Molecular detection of Angiostrongylus vasorum in gastropods in Surrey, UK
}

\author{
L. Hicklenton $^{1} \cdot$ M. Betson ${ }^{1}$ (D \\ Received: 25 September 2018 / Accepted: 19 December 2018 / Published online: 26 January 2019 \\ (C) The Author(s) 2019
}

\begin{abstract}
Surrey, a county in southern England, is a hot spot for angiostrongylosis in domestic dogs but there have been no investigations into the intermediate hosts of Angiostrongylus vasorum in this area. This study aimed to determine the prevalence of A. vasorum in gastropods in Guildford, the most populous town in Surrey, and to ascertain which gastropod species can act as intermediate hosts for A. vasorum. Gastropods $(n=97)$ were sampled in six locations, representing urban, suburban and rural environments, and identified to species based on morphological features. A PCR assay was used to detect A. vasorum DNA in gastropod tissue and the species of infected specimens was confirmed by sequencing of mitochondrial genes. 4.1\% (4/97) of sampled gastropods and $9.1 \%(4 / 44)$ of sampled slugs were A. vasorum positive. Infected gastropod species were Arion rufus $(n=3)$ and Deroceras invadens ( $n=1)$, the first description of the latter species as a potential intermediate host for $A$. vasorum. Two infected slugs were sampled in urban environments and two in suburban environments. The results demonstrate that there is a risk of transmission of A. vasorum to domestic dogs from the gastropod population in urban and suburban areas of Guildford.
\end{abstract}

Keywords Angiostrongylus vasorum · Gastropod · Deroceras invadens $\cdot$ Arion rufus

\section{Introduction}

The lungworm Angiostrongylus vasorum causes the serious and potentially fatal disease angiostrongylosis in domestic dogs (Elsheikha et al. 2014). It can also infect wild carnivores, such as red foxes, which are important reservoir hosts. In the UK, there are established hyperendemic foci of the parasite in Wales and southeast England and newer endemic foci in the north of England and Scotland (Helm et al. 2009; Kirk et al. 2014). Angiostrongylus vasorum has an indirect lifecycle with larval development taking place within a gastropod intermediate host. Dogs are infected through ingestion of gastropods carrying infective L3 larvae. A number of gastropod species have been implicated as intermediate hosts for A. vasorum in

Handling Editor: Julia Walochnik

Electronic supplementary material The online version of this article (https://doi.org/10.1007/s00436-018-6191-1) contains supplementary material, which is available to authorized users.

M. Betson

m.betson@surrey.ac.uk

1 School of Veterinary Medicine, University of Surrey, Guildford GU2 7AL, UK the UK (Aziz et al. 2016; Helm et al. 2015; Jefferies et al. 2009; Patel et al. 2014). Surrey, a county in southern England (population 1.1 million), is a hot spot for angiostrongylosis in domestic dogs (Chapman et al. 2004; Kirk et al. 2014). To date, there have been no investigations into the intermediate hosts of $A$. vasorum in this area. This study aimed to determine the prevalence of A. vasorum in gastropods in the area of Guildford, the most populous town in Surrey, and to ascertain which gastropod species can act as intermediate hosts for A. vasorum.

\section{Materials and methods}

A total of 97 gastropods were collected from six sites around Guildford in Autumn 2016. Collection sites were chosen based on accessibility and to represent urban, sub-urban and rural environments. Urban sites were in built up areas such as housing estates along the sides of paths and roads. Suburban sites were in open areas such as parks surrounded by built up areas. Rural sites were away from built up areas and included woodland. Gastropods were collected using forceps (and a torch if needed) between the hours of 17:00 and 11:30 and were found by looking on the ground, in hedgerows and in the 
Fig. 1 Neighbour joining tree based on cytochrome oxidase I (COI) sequences representing all clades of the Agriolimacidae family. Values next to branches indicate percentage bootstrap support. The asterisk $(*)$ indicates the Agriolimacidae specimen collected in this study

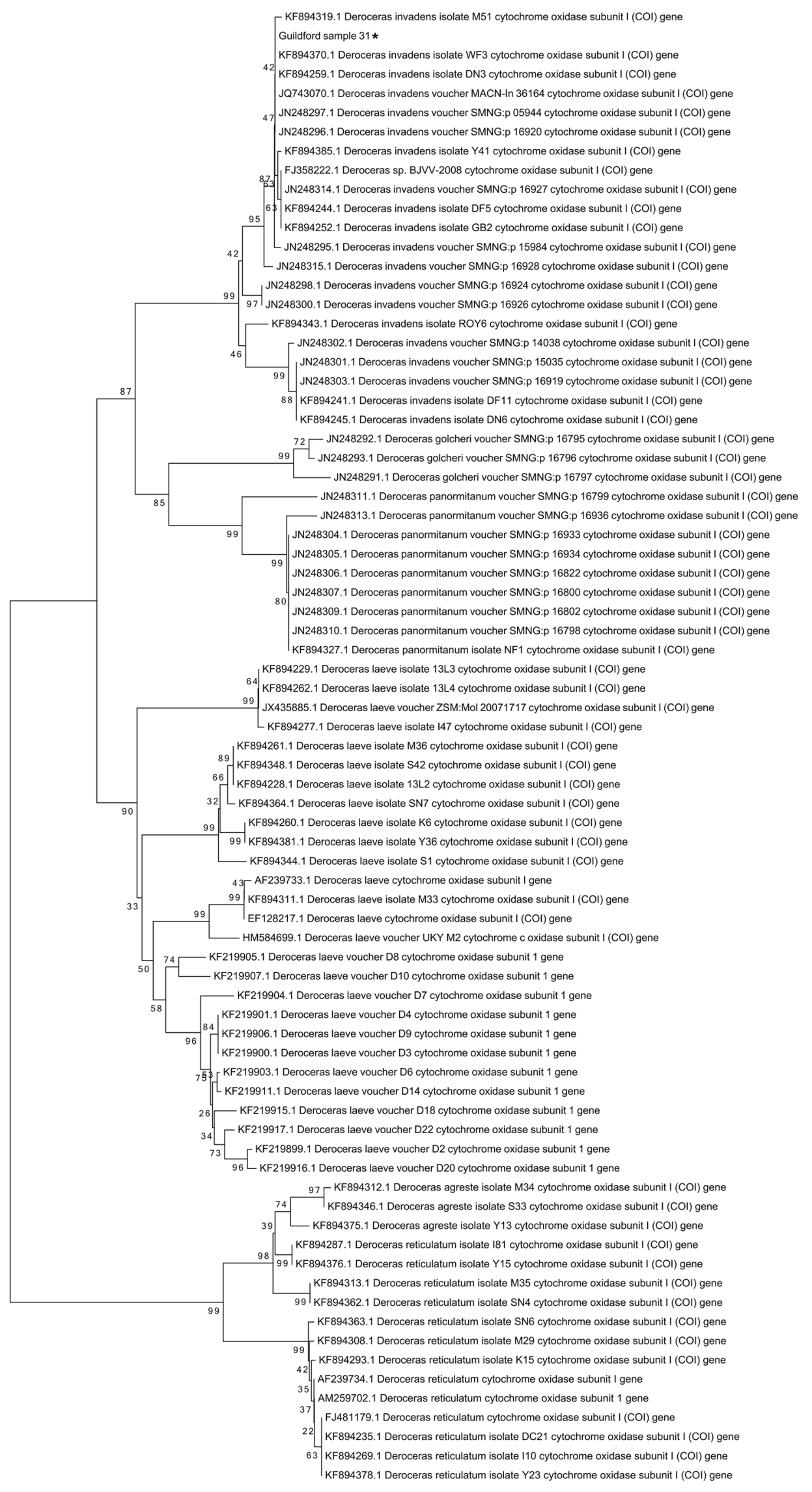

KF894319.1 Deroceras invadens isolate M51 cytochrome oxidase subunit I (COI) gene Guildford sample 31 *

KF894370.1 Deroceras invadens isolate WF3 cytochrome oxidase subunit I (COI) gene Q743070.1 Deroceras invadens voucher MACN-In 36164 cytochrome oxidase subunit I (COI) gene 4385.1 Deroceras invadens isolate $Y 41$ cytochrome oxidase subunit I (COI) gen Deroceras sp. BJV-2008 cylochrome oxidase subunit I (COI) gene KF894244.1 Deroceras invadens isolate DF5 cytochrome oxidase subunit I (COI) gene (15olate GB2 cytochrome oxidase subunit I (COI) gene .

- JN248302.1 Deroceras invadens voucher SMNG:p 14038 cytochrome oxidase subunit I (COI) gene KF894229.1 Deroceras laeve isolate 13L3 cytochrome oxidase subunit I (COI) gen KF894262.1 Deroceras laeve isolate 13L4 cytochrome oxidase subunit I (COI) gen

(K59261.1 Deroceras laeve isolate M36 cytochrome oxidase subunit I (COI) gene

KF894348.1 Deroceras laeve isolate $\mathrm{S} 42$ cytochrome oxidase subunit I (COI) gen

66 KF894228.1 Deroceras laeve isolate 13L2 cytochrome oxidase subunit I (COI) gen

2 KF894364.1 Deroceras laeve isolate SN7 cytochrome oxidase subunit I (COI) gene

99 KF894311.1 Deroceras laeve isolate M33 cytochrome oxidase subunit I (COI) gene

EF128217 1 Deroceras laeve cytochrome oxidase subunit I (COI) gene

05.1 eroceres

KF219907 1 Deroceras leve voucher D10 cytochrome oxidase subunit 1 gen

KF219904.1 Deroceras laeve voucher D7 cytochrome oxidase subunit 1 gene

KF219899.1 Deroceras laeve voucher D2 cytochrome oxidase subunit 1 gen

74 KF894346.1 Deroceras agreste isolate S33 cytochrome oxidase subunit I (COI) gene

39 KF894375.1 Deroceras agreste isolate Y13 cytochrome oxidase subunit I (COI) gene

Deroceras reticulatum isolate $\mathrm{K} 15$ cytochrome oxidase subunit I (COI) gene

AM259702.1 Derocers relicula cylochion 1 ge

FJ481179.1 Deroceras reticulatum cytochrome oxidase subunit I (COI) gen KF894378.1 Deroceras reticulatum isc 
undergrowth. Gastropods were identified to species using morphological keys (Kerney and Cameron 1994; Rowson et al. 2014a) and then frozen at $-20^{\circ} \mathrm{C}$.

DNA was extracted from 10 to $20 \mathrm{mg}$ of gastropod foot tissue using the DNeasy Blood and Tissue kit (Qiagen). Angiostrongylus vasorum DNA was detected by PCR using the AvasF and AvasR primers (Helm et al. 2009). For molecular identification of A. vasorum-positive gastropods, cytochrome c oxidase subunit I (COI) and 16S rDNA genes were amplified using LCO1490 and HCO2198 (Folmer et al. 1994) and 16S-1 and 16S-2 (Barr et al. 2009) primers, respectively. Each $25 \mu \mathrm{l}$ PCR reaction contained $12.5 \mu \mathrm{l}$ MyTaq HS Red mix (Bioline, London, UK), 0.4 pmole of the forward and reverse primers and $2 \mu \mathrm{l}$ of eluted DNA. Cycling conditions were as follows: $95^{\circ} \mathrm{C}$ for $1 \mathrm{~min}$, then 30 cycles of $95^{\circ} \mathrm{C}$ for $15 \mathrm{~s}, 55^{\circ} \mathrm{C}$ (Avas) $/ 42{ }^{\circ} \mathrm{C}(\mathrm{CO} 1) / 50{ }^{\circ} \mathrm{C}(16 \mathrm{~S})$ for $15 \mathrm{~s}$ and $72{ }^{\circ} \mathrm{C}$ for $15 \mathrm{~s}$. PCR products were submitted for Sanger sequencing. BLAST searches of GenBank indicated that A. vasorum positive gastropods belonged to the larger Arionidae $(n=3)$ and Agriolimacidae $(n=1)$ families. $16 \mathrm{~S}$ sequences representing all clades of the larger Arionidae were aligned with $16 \mathrm{~S}$ sequences of the Arionidae specimens using CLUSTALW in MEGA v6 (Tamura et al. 2007). The alignment was used to construct a neighbour joining tree based on Kimura 2-parameter distance (Rowson et al. 2014a). Bootstrapping (1000 replicates) was carried out to test branch reliability. Similar analysis was carried out for the Agriolimacidae specimen using COI sequences.

\section{Results and discussion}

The 97 gastropods collected were classified into nine families, 15 genera and 21 species (see Supplementary Table). Differentiation between certain species (e.g., Cepaea hortensis and $C$. nemoralis) was not always possible based on morphology. There was a significant association between gastropod family and location type (Fisher's exact test $p<0.0001$ ), likely due to local ecological factors such as vegetation which favour particular families. Similar slug species were sampled in Swansea and Bristol (Aziz et al. 2016), although the relative proportions of species vary in the different locations. Interestingly, some A. vasorum-negative gastropod species sampled in Guildford have been implicated as intermediate hosts for A. vasorum, suggesting that they could also play a role in local transmission (Ferdushy and Hasan 2010; Helm et al. 2015).

Four $(4.1 \%)$ of the 97 gastropods examined were positive for A. vasorum infection by PCR. All were slugs, meaning that $9.1 \%$ (4/44) of slugs were A. vasorum positive. The A. vasorum prevalence in gastropods is comparable to that recorded in Glasgow (Helm et al. 2015). The prevalence in slugs is higher than in London (Patel et al. 2014) and in Bristol, and lower than in
Swansea (Aziz et al. 2016). Explanations for geographical differences could include variations in gastropod density and species composition, effects of local environment on parasite transmission and methods used for $A$. vasorum detection.

Sequencing of mitochondrial gene regions of $A$. vasorumpositive gastropods revealed that three belonged to the larger Arionidae family and the one to the Agriolimacidae family. Phylogenetic analysis of $16 \mathrm{~S}$ sequences revealed that the three Arionidae gastropods belonged to the European Arion rufus clade (Supplementary Fig. 1), whereas similar analysis of COI sequences demonstrated that the A. vasorum-positive Agriolimacidae specimen belonged to the Dercoceras invadens clade (Fig. 1) (Rowson 2016). Two positive Ar. rufus specimens were found in urban environments. The two other positive specimens were found in suburban environments. Infected Ar. rufus slugs have been reported in the UK and Europe (Aziz et al. 2016; Eckert and Lammler 1972; Ferdushy et al. 2009; Guilhon and Cens 1973; Helm et al. 2015; Patel et al.2014). Arion rufus is a large slug species and may be more likely to be ingested by dogs than smaller species. This study represents the first report of $D$. invadens as a potential intermediate host for A. vasorum, although natural infections of other Deroceras species have been described (Ferdushy and Hasan 2010; Jefferies et al. 2009; Lange et al. 2018). Deroceras invadens is widely distributed throughout the UK and Europe, typically occurring in disturbed, urban and roadside sites (Rowson et al. 2014b), suggesting ample opportunities for dogs to encounter this species.

In conclusion, there is a risk of transmission of $A$. vasorum to domestic dogs from the gastropod population in urban and suburban areas of Guildford. In addition, a new potential intermediate host for A. vasorum has been identified. Further work is needed to confirm whether there are differences in prevalence between urban, suburban and rural areas and investigate seasonal variations in transmission risk.

Acknowledgments We are extremely grateful to Prof Mark Fox and Dr. Jocelyn Riggins at the Royal Veterinary College for providing Angiostrongylus vasorum positive control DNA for PCR reactions.

Funding This work was supported by the European Scientific Counsel Companion Animal Parasites (ESCCAP) and the University of Surrey.

\section{Compliance with ethical standards}

Conflict of interest The authors declare that they have no conflict of interest.

Ethical approval A University of Surrey NASPA ethical review assessment indicated that ethical review was not required. No protected gastropod species were sampled.

Open Access This article is distributed under the terms of the Creative Commons Attribution 4.0 International License (http:// creativecommons.org/licenses/by/4.0/), which permits unrestricted use, distribution, and reproduction in any medium, provided you give 
appropriate credit to the original author(s) and the source, provide a link to the Creative Commons license, and indicate if changes were made.

Publisher's note Springer Nature remains neutral with regard to jurisdictional claims in published maps and institutional affiliations.

\section{References}

Aziz NA et al (2016) Distribution of Angiostrongylus vasorum and its gastropod intermediate hosts along the rural-urban gradient in two cities in the United Kingdom, using real time PCR. Parasit Vectors 9: 56. https://doi.org/10.1186/s13071-016-1338-3

Barr NB, Cook A, Elder P, Molongoski J, Prasher D, Robinson DG (2009) Application of a DNA barcode using the 16S rRNA gene to diagnose pest Arion species in the USA. J Mollus Stud 75:187191. https://doi.org/10.1093/mollus/eyn047

Chapman PS, Boag AK, Guitian J, Boswood A (2004) Angiostrongylus vasorum infection in 23 dogs (1999-2002). J Small Anim Pract 45: 435-440. https://doi.org/10.1111/j.1748-5827.2004.tb00261.x

Eckert J, Lammler G (1972) Angiostrongylose bei Mensch Und Tier. Z Parasitenkd 39:303-322. https://doi.org/10.1007/BF00329093

Elsheikha HM, Holmes SA, Wright I, Morgan ER, Lacher DW (2014) Recent advances in the epidemiology, clinical and diagnostic features, and control of canine cardio-pulmonary angiostrongylosis. Vet Res 45:92. https://doi.org/10.1186/s13567-014-0092-9

Ferdushy T, Hasan MT (2010) Angiostrongylus vasorum: the 'French heartworm'. Parasitol Res 107:765-771. https://doi.org/10.1007/ s00436-010-2026-4

Ferdushy T, Kapel CM, Webster P, Al-Sabi MN, Gronvold J (2009) The occurrence of Angiostrongylus vasorum in terrestrial slugs from forests and parks in the Copenhagen area, Denmark. J Helminthol 83: 379-383. https://doi.org/10.1017/S0022149X09377706

Folmer O, Black M, Hoeh W, Lutz R, Vrijenhoek R (1994) DNA primers for amplification of mitochondrial cytochrome $\mathrm{c}$ oxidase subunit I from diverse metazoan invertebrates. Mol Mar Biol Biotechnol 3: 294-299

Guilhon J, Cens B (1973) Angiostrongylus vasorum (Baillet, 1866) etude biologique et morphologique. Ann Parastiol Hum Comp 48:567596. https://doi.org/10.1051/parasite/1973484567
Helm J, Gilleard JS, Jackson M, Redman E, Bell R (2009) A case of canine Angiostrongylus vasorum in Scotland confirmed by PCR and sequence analysis. J Small Anim Pract 50:255-259. https:// doi.org/10.1111/j.1748-5827.2009.00741.x

Helm J, Roberts L, Jefferies R, Shaw SE, Morgan ER (2015) Epidemiological survey of Angiostrongylus vasorum in dogs and slugs around a new endemic focus in Scotland. Vet Record 177: 46. https://doi.org/10.1136/vr.103006

Jefferies R, Morgan ER, Shaw SE (2009) A SYBR green real-time PCR assay for the detection of the nematode Angiostrongylus vasorum in definitive and intermediate hosts. Vet Parasitol 166:112-118. https:// doi.org/10.1016/j.vetpar.2009.07.042

Kerney MP, Cameron RAD (1994) Land snails of Britain and north-west Europe. HaperCollins Publishers, London

Kirk L, Limon G, Guitian FJ, Hermosilla C, Fox MT (2014) Angiostrongylus vasorum in Great Britain: a nationwide postal questionnaire survey of veterinary practices. Vet Record 175:118. https:// doi.org/10.1136/vr.102196

Lange MK, Penagos-Tabares F, Hirzmann J, Failing K, Schaper R, van Bourgonie YR, Backeljau T, Hermosilla C, Taubert A (2018) Prevalence of Angiostrongylus vasorum, Aelurostrongylus abstrusus and Crenosoma vulpis larvae in native slug populations in Germany. Vet Parasitol 254:120-130. https://doi.org/10.1016/j. vetpar.2018.03.011

Patel Z, Gill AC, Fox MT, Hermosilla C, Backeljau T, Breugelmans K, Keevash E, McEwan C, Aghazadeh M, Elson-Riggins JG (2014) Molecular identification of novel intermediate host species of Angiostrongylus vasorum in Greater London. Parasitol Res 113: 4363-4369. https://doi.org/10.1007/s00436-014-4111-6

Rowson B, Anderson R, Turner JA, Symondson WOC (2014a) The slugs of Britain and Ireland: undetected and undescribed species increase a well-studied, economically important fauna by more than $20 \%$. PLoS One 9:e91907. https://doi.org/10.1371/journal.pone.0091907

Rowson B, Turner J, Anderson R, Symondson B (2014b) Slugs of Britain and Ireland. RSC Publications, Telford

Tamura K, Dudley J, Nei M, Kumar S (2007) MEGA4: Molecular Evolutionary Genetics Analysis (MEGA) software version 4.0. Mol Biol Evol 24:1596-1599. https://doi.org/10.1093/molbev/ msm092 